\title{
APROXIMACIÓN A LA FIGURA DE GABINO - ALEJANDRO CARRIEDO
}

\author{
Mario PAZ GONZÁLEZ \\ Instituto “Juan del Encina”. León.
}

\section{Introducción}

No siempre resulta fácil la adscripción de un autor, que haya desarrollado su obra en época reciente, a una determinada promoción poética, por ello se observa que en numerosas ocasiones el criterio metodológico a seguir, al respecto, sea el de orientarse según los esquemas propuestos por algunas de las antologías más populares de la literatura que se está estudiando. Así ha sucedido al menos con la poesía española de posguerra, para cuyo estudio se han utilizado textos como la Antología consultada de la joven poesía española de Francisco Ribes; Un cuarto de siglo de poesía española (1939-1964) o Veinte años de poesía española. Antología 1939-1959 de José María Castellet y Antología de la nueva poesía española de José Batlló. Sin embargo, no puede dejar de señalarse, como hace Vilamura ${ }^{1}$, la poca conveniencia que muestran algunas de las 'etiquetas' aparecidas en estas obras, como la primera de las citadas de Castellet, cuya influencia ha sido enorme en lo que se refiere a catalogación por parte de la crítica de diversos autores de la época. Así, muchos de los poetas que aparecen en el citado libro considerados en el apartado de 'poetas sociales', como es el caso de GabinoAlejandro Carriedo con su poemario El corazón en un puño (1959), tal vez no lo serían si consideramos el conjunto de su obra, pues en muchos de ellos alentó una profunda preocupación por el lenguaje y la forma, evitando esa expresión desmañada, tendente al panfleto desgraciadamente tan frecuente, y no carente de ejemplos, en la denominada 'poesía social'.

En el caso concreto de Gabino-Alejandro Carriedo no tenemos precisamente a un poeta de fácil adscripción a tal o cual escuela, y la imagen que de su obra nos ofrece la crítica varía considerablemente de unas décadas a otras. Sin embargo, tanto el hecho de que sus primeros libros de filiación vanguardista hayan permanecido inéditos, como el de que algunas de sus obras posteriores contengan un cierto componente de crítica social hace perfectamente comprensible esa ubicación de su poesía, por buena parte de los estudiosos, entre los autores de la generación del medio siglo. Como señala Ayuso² no era extraño que "en los recuentos oficialistas de la posguerra" apareciese las más de las veces "descentrado de todo movimiento", algo que atribuye a que "la historia de la poesía española -como de la literatura en general- se ha hecho desde supuestos extraliterarios".

\section{2. Época}

Si hemos de analizar la época en que se formó el palentino, no podemos obviar el hecho de que la guerra civil tuvo unas consecuencias nefandas para la vida cultural española, dejando tras sí un panorama desolador, pues a la muerte o el exilio de un gran número de intelectuales habría que sumar el exilio interior de aquellos que no

\footnotetext{
${ }^{1}$ Martín Vilamura, "Notas para un estudio sobre la poesía española de postguerra”, Camp de l'arpa 86, 1981, 13-16.

${ }^{2}$ Ayuso, César Augusto, "Gabino-Alejandro Carriedo y la poesía española de posguerra", Mairena 19, 1985, 89-92.
} 
tuvieron más remedio que quedarse. En el intento de reconstrucción de ese otro panorama cultural (el de las décadas anteriores al conflicto bélico) insustituible, que algunos, han dado en denominar la "segunda Edad de Oro" de la cultura española, habrían de surgir diferentes movimientos que, en lo que a poesía se refiere, trataban de reinventar el pasado para así paliar el vacío creativo surgido tras la contienda.

Se ofrecía, pues, una clara división de los creadores en dos vertientes enfrentadas. Por un lado los llamados 'garcilasistas', reunidos en torno a la revista Garcilaso (1943-1946) de José García Nieto y que protagonizaban una tendencia caracterizada por entender la creación poética como una huida de la realidad en busca de lo bello, con un cuidado formal inspirado en nuestros clásicos del Siglo de Oro (entre estos autores podría citarse nombres como Dionisio Ridruejo, Luis Rosales, Juan y Leopoldo Panero o Luis Felipe Vivanco); mientras que por otro lado tenemos los poetas del llamado 'desarraigo', que se aglutinan en torno a la revista Espadaña capitaneada en León por los poetas 'tremendistas' Victoriano Crémer y Eugenio de Nora, y que seguirán la estela de Dámaso Alonso, sobre todo a partir de dos libros que resultarán capitales de este período, Hijos de la ira y Oscura noticia.

En estos años comenzará también a publicar Gabino-Alejandro Carriedo, primero desde la provincia, en el grupo Nubis de su Palencia natal, para pasar luego a Madrid, donde tomaría contacto con el grupo postista. Su Poema de la condenación de Castilla (1946), editado en Palencia por Nubis, lo adscribirá temporalmente a los tremendistas. Algún crítico ${ }^{3}$ dotado de gran lucidez supo ver ya en esta obra una preocupación por la forma de la que carecían la mayor parte de los tremendistas y un deseo de clasicismo que pronto lo llevará a sentirse afín al movimiento postista (después de los ismos) encabezado por Carlos Edmundo de Ory, Silvano Sernesi y Eduardo Chicharro.

\section{El Postismo}

El Postismo fue un movimiento singular que no lo tuvo precisamente nada fácil para hacerse un hueco en una poesía de posguerra marcada por esas dos vertientes citadas. Resultaba demasiado innovador, pese a su estirpe, según Fernández Molina, modernista. Además no faltaron los conflictos internos que lo irían minando poco a poco, como el surgido a raíz de la entrevista en Radio S.E.U. a Gabino-Alejandro Carriedo y a Félix Casanova de Ayala ${ }^{4}$, pues Ory aludió en alguna ocasión al intento de estos jóvenes, junto con Crespo, de hacerse con el control del grupo.

Estos acontecimientos, unidos a la dificultad que representaba el codificar un lenguaje poético propio basado fundamentalmente en la concepción de la escritura como un espacio de libertad, debieron ser las causas que dieron al traste con el Postismo, un movimiento que había asumido como propia la ardua tarea de incorporar la poesía española a las nuevas tendencias vanguardistas imperantes en la Europa del medio siglo, sirviendo de este modo como continuación de la apertura bruscamente interrumpida con la guerra. Su pretensión un tanto ambiciosa pasaba ni más ni menos que por utilizar los descubrimientos llevados a cabo por las vanguardias en

\footnotetext{
${ }^{3}$ Pilar Gómez Bedate, "Cinco poetas españoles”, 1964, pp.10-11.

${ }^{4}$ Dicha entrevista aparece transcrita en Jaume Pont, El postismo. Un movimiento estético-literario de vanguardia, Barcelona (Edicions del Mall) 1987.
} 
pos de su aprovechamiento racional, difiriendo así, en la raíz de sus planteamientos, del automatismo y otras costumbres propias del grupo surrealista de Breton. Para Francisco Nieva5, el Postismo fue un movimiento genuinamente español que debería gozar del lugar que le corresponde dentro de la historia de la literatura patria, pues se anticipó a su tiempo, resultando casi profético en muchos aspectos al abrir el camino hacia la posmodernidad con varias décadas de antelación a su efervescencia.

Gabino-Alejandro Carriedo se había unido a los postistas acompañado por Ángel Crespo, quien compartía el mismo deseo renovador del lenguaje poético sin por ello dejar de ser respetuoso con la tradición. Sin embargo las diferencias aludidas con los fundadores, junto con sus distintos planteamientos, como expone $\mathrm{M}^{\mathrm{a}}$. Isabel Navas Ocaña ${ }^{6}$ (entre otras razones porque Crespo y Carriedo tenían una mayor preocupación por lo social) llevarían a una escisión de ambos del grupo inicial.

\section{Las revistas}

Será con Ángel Crespo precisamente con quien lleve a cabo dos empresas editoriales de notable éxito: El Pájaro de Paja (Madrid, 1950), unidos a Federico Muelas, y Poesía de España (1960). Crespo fundará además Deucalión (Ciudad Real, 1951). El mayor mérito de todas estas publicaciones, integradas en lo que Fanny Rubio 7 define como la "segunda etapa" de la posguerra, iniciada tras la desaparición de Espadaña de León, es el de ser representativas de un movimiento renovador de la cultura, junto con otras publicaciones de la misma estirpe, tales como Postismo o La cerbatana. Por esa misma razón todas ellas presentan un eclecticismo que las lleva a contar entre su nómina de colaboradores habituales con nombres tan dispares, y aún opuestos, como Chicharro, de Ory, Labordeta, Fernando Quiñones, Gloria Fuertes, Juan Eduardo Cirlot, Blas de Otero, Gabriel Celaya, Carmen Conde, Rafael Millán, Emilio Prados, Max Aub, Celso Emilio Ferreiro, Dámaso Alonso, Jorge Guillén, Vicente Aleixandre o Gerardo Diego. Por otro lado, tan importante o más que las propias revistas resultará la publicación aneja de una colección de libros de algunos de estos colaboradores. Todas estas empresas editoriales captan de un modo $u$ otro la complejidad del momento y muestran un corolario de tendencias que harían tambalearse al realismo social frente a estas otras nuevas vías de exploración. Además, muchas de estas publicaciones habrían de servir de puente hacia la generación más joven, integrada por nombres como Jaime Gil de Biedma, José Agustín Goytisolo, Carlos Barral, Jesús López Pacheco, José Esteban, Ángel Valente, José Manuel Caballero Bonald, Ángel González, Leopoldo de Luis, Carlos Bousoño, etc. Especialmente Poesía de España, que jugó además un papel decisivo en la difusión de las literaturas extranjeras.

En la etapa de Poesía de España Carriedo se distanciará más todavía del Postismo realizando un acercamiento progresivo hacia el 'realismo social' que lo llevará casi a renegar de su etapa anterior. Al menos eso es lo que se intuye en alguna entrevista realizada en estos años ${ }^{8}$. Él mismo llegará a calificar su modo de hacer poesía de 'in-

\footnotetext{
${ }^{5}$ Francisco Nieva, "El Postismo una vez más", $A B C$ (22-7-1984), p.3.

${ }^{6} \mathrm{M}^{\mathrm{a}}$ Isabel Navas Ocaña, El Postismo, Cuenca (El toro de barro) 2000, pp.69-82.

${ }^{7}$ Fanny Rubio, Las revistas poéticas españolas (1939-1975), Madrid (Turner) 1976.

${ }^{8}$ En Rubén Vela, "Gabino-Alejandro Carriedo", Ocho poetas españoles Buenos Aires (Dead Weight) 1965, p.43, podemos leer: Con la cabeza y el corazón me adscribo al movimiento realista que informa definitivamente a la nueva hora de la Poesía y el Arte. Por diferentes caminos, desde los primeros versos responsables, he pretendido vivir en el tiempo y comunicar-
} 
formativismo poético', dada su profesión de periodista, impregnando en cierta medida su discurso del mesianismo que imperaba en la lírica social. Es por ello que buena parte de la crítica adhiere así los libros escritos en este periodo al 'realismo social', colocando a su autor al lado de los poetas de Espadaña, Victoriano Crémer y Eugenio de Nora, y también junto a nombres como Gabriel Celaya, Blas de Otero, Ángela Figuera, Ramón de Garciasol o Leopoldo de Luis. Sin embargo, sabemos que entre las lecturas del poeta ya figuraban algunos escritoress luso-brasileños, como Joao Cabral de Melo Neto o Drumond de Andrade, que habían de influir tanto en periodos posteriores de su obra.

\section{Carriedo, poeta social}

Todos estos cambios en la trayectoria de Carriedo son, sin embargo, el resultado de una evolución coherente, como ha señalado Rafael Ballesteros ${ }^{9}$, marcada por la profunda asimilación de las diferentes tendencias por las que había transitado, impregnándolas a su vez de una honda preocupación humana, que no rehuirá la utilización inteligente del humor y de la ironía. Esta evolución habría comenzado a advertirse ya desde los primeros libros, y se manifestaría como un proceso gradual, desde el 'tremendista' Poema de la Condenación de Castilla (1946), pasando por La piña sespera (1948) bajo el influjo de Chicharro, de Ory, el dadaísmo y el surrealismo hasta La flor del humo (1949), Los animales vivos (1951) y Del mal el menos (1952), libros que para Martínez Sarrión ${ }^{10}$ constituyen la etapa de más amplia madurez del poeta, pues en ellos ya palpita de un modo fehaciente la influencia de poetas brasileños o del portugués Pessoa. Persistirá además en esta época, y a lo largo de toda su obra, incluso en la poesía inédita o en los libros póstumos, el humor heredado del Postismo. Para Galán ${ }^{11}$ los últimos libros citados son herederos del surrealismo y en ellos se encerraría parte del origen del tan traído y llevado 'realismo mágico', pues no sólo se va a representar la realidad con palabras, sino a hacer que a través de la vivencia simbólicamente reflejada la palabra misma merezca ser real. Se trasciende, pues, la realidad a través de la exploración del lenguaje consiguiendo con ello que hasta el asunto más nimio se convierta en materia poética para mostrar con un asomo de ironía el absurdo del mundo.

Pero la etapa más social de Gabino-Alejandro Carriedo habría de comenzar a desarrollarse en toda su plenitud, en medio del ambiente politizado de la España de los sesenta, con Las alas cortadas (1959) y con dos libros que, si bien por su título (El corazón en un puño de 1961 y Política agraria de 1963) podrían participar del ambiente contestatario del momento, presentan un tono de humor distanciado y pleno cargado de una ironía que llega a rozar por momentos el sarcasmo. Aquí Lechner ${ }^{12}$ parece coincidir plenamente con Antonio Martínez Sarrión al considerar que Política agraria (1963) no se halla, ni mucho menos, entre lo mejor de la producción de Carriedo. De

\footnotetext{
me de verdad con el hombre.

${ }^{9}$ Rafael Ballesteros, "Gabino-Alejandro Carriedo", Jano 40, 1973, 130.

${ }^{10}$ Antonio Martínez Sarrión, "Prólogo" en Gabino-Alejandro Carriedo, Nuevo compuesto descompuesto viejo (Poesía 19481979), Madrid (Hiperión) 1980, pp.7-23.

${ }^{11}$ Joaquín Galán, "Gabino-Alejandro Carriedo o la escritura como espacio de libertad”, Hora de poesía, 40-41, 1985, pp. 140-165.

12 J. Lechner, "La marea ascendente de la poesía social" en F. Rico y A. Indurain, Historia y crítica de la literatura española. Época contemporánea (1939-1980), Barcelona (Crítica) 1981.
} 
todos modos, el palentino no parece adoptar esa actitud prefijada de todo poeta social y ésta se diluye mediante el constante uso del humor y de la ironía ya aludidos que sirven incluso para relatar episodios trágicos consiguiendo con ello un distanciamiento que acentúa el dramatismo y provoca una reflexión o el desconcierto del lector. Para Fanny Rubio ${ }^{13}$, Carriedo navegaba, en realidad, ajeno a las modas y tendencias en boga, integrando 'verticalmente' en su obra varias de las escuelas de las que participaba su lírica, pero imprimiéndole un humor personal, convirtiéndose de este modo en un autor 'discordante y excepcional'. Carriedo, como Labordeta, representaría, dentro de su generación, el caso del poeta anticipado a su tiempo, pues en su obra se pueden rastrear algunas de las claves de la evolución experimentada por la joven poesía española de generaciones posteriores que, bajo el signo vanguardista aparente, encerraría una actitud revolucionaria y la incorporación de lo humano al poema.

Santiago Amón ${ }^{14}$, en un artículo fundamental para entender la vida y la obra de Carriedo, contradice a buena parte de la crítica y nos dice que su perfil individual y sorprendente lo alejaría de toda clasificación y encasillamiento fáciles y, desde luego, de la siempre dudosa adscripción de su obra a la poesía denominada 'social' por su heterogeneidad y su humor netamente alejados de cierto maniqueísmo un tanto ramplón en que derivaron muchos de los poetas de esta tendencia. Algunos críticos como José Batlló ${ }^{15}$ subrayan la coherencia estilística que preside el conjunto de su obra pese a haber transitado por terrenos tan rudos y dispares como el 'tremendismo', el Postismo, el 'realismo social' o el 'realismo mágico', pues consigue dotar a todas sus composiciones de una enorme precisión lingüística, realizando con ello una búsqueda constante del vocablo adecuado, pero con una coherencia tal que no niega, antes al contrario, una evidente evolución presidida siempre por la diafanidad del lenguaje y por un inconmovible sentido del humor.

En 1966 Carriedo publica un libro escrito años antes, en 1951, en plena etapa postista, titulado Los animales vivos, que bajo la forma de un bestiario encierra ideas sociales y humanas en muchos de sus poemas.

\section{El Concretismo}

Pero quizás otro acontecimiento de su biografía ocurrido ese año será más trascendente de cara a su evolución poética posterior, pues se situará ahora al frente de la revista Nueva forma, dedicada a la arquitectura, el diseño y las artes plásticas. Comienza aquí una nueva etapa en la que se familiariza con las teorías del constructivismo y del Concretismo, cuya influencia se plasmará en 1973 con la publicación del poemario Los lados del cubo (con cubierta de Chillida). Se trata de un libro en el que se muestra la influencia de los autores del modernismo luso-brasileño (nada que ver con el movimiento encabezado por Darío), especialmente de Joao Cabral de Melo Neto, pero también de Carlos Drummond de Andrade. A esto hay que sumar su creciente interés, debido a motivos profesionales, por la obra de arquitectos, escultores y artistas plásticos en general, de ahí que no sea raro encontrar en los textos que inte-

\footnotetext{
${ }^{13}$ Fanny Rubio, "Surrealismo, compromiso y humor en solitario", El País 22-6-1980.

${ }^{14}$ Santiago Amón, "De Manrique a Carriedo". ABC (30-9-1981), p.3.

${ }^{15}$ José Batlló, "El poeta Gabino-Alejandro Carriedo", La Vanguardia (17-9-1981), p.19.
} 
gran el libro dedicatorias a, entre otros, Leonardo da Vinci, Miró, Rodin, Picasso, Chillida, etc. De esta suma de influencias surge una poesía diferente a la que el palentino había escrito hasta el momento, pues nos encontramos ahora ante una lírica que entierra sus raíces en el Concretismo, pero que, al mismo tiempo, entronca de algún modo con su obra de etapas anteriores. Para Ángel Crespo ${ }^{16}$, la influencia de Cabral de Melo se manifiesta de forma casi avasalladora en este libro al que califica también como el más discutible en cuanto a su calidad. Amador Palacios ${ }^{17}$, en su biografía del autor, lo calificará también de obra 'fallida'. Frente a los libros anteriores del poeta su escritura resulta ahora, en comparación, árida por su condensación y esquematismo, fatigosa por el recurso al tecnicismo del vocablo. Tal vez se debiese esto a esa continua búsqueda de una depuración creciente y de más y mejores formas expresivas, búsqueda en el fondo llevada a cabo por el palentino a lo largo de toda su trayectoria.

Los últimos textos de Carriedo, incluidos en la antología Nuevo compuesto descompuesto viejo bajo el epígrafe aglutinador de Poesía inédita, revelan sin embargo una lírica de raíz más íntima, en la que las preocupaciones pasan a ser la huida del tiempo y la obsesión por la muerte inevitable. Temas que reaparecerán de nuevo en uno de sus libros póstumos, Lembranças e deslembranças, escrito en portugués y donde, para Martínez Sarrión ${ }^{18}$, la presencia de la muerte alcanza un carácter profético, anticipándose a la del propio autor, acaecida antes de su publicación, por lo que Carriedo revelaría de este modo su condición de vate "en su sentido etimológico de adivino". Ayuso $^{19}$ considera a éste uno de los libros fundamentales de la trayectoria del palentino, por lo denso y depurado de sus versos que confirman su madurez poética una vez superadas las etapas anteriores de búsqueda de una voz propia. Por ello, en el libro se perciben ciertos ecos de su obra anterior que ahora emergen en su grado máximo a través de la desnudez expresiva y conceptual cercana, dice Ayuso, a la llamada "poesía de la experiencia" a la que también se acercarían algunas composiciones de la "Poesía inédita" aparecida en Nuevo compuesto descompuesto viejo, y una buena parte de las que se incluyen en su otra obra póstuma El libro de las premoniciones, poemario que, como señala Francisca Domingo en el prólogo ${ }^{20}$, está dotado de una unidad interna indiscutible pues en él se hallan presentes muchas de las constantes de su obra: la reflexión en torno al tiempo de historia, la premonición de la muerte, la creación de un espacio que genere un impulso vivificante, la nostalgia de futuro, el sarcasmo, la experiencia vital...

\section{Algunas conclusiones}

Si hemos de analizar, pues, la obra de Carriedo a ojos de la crítica y en su conjunto, podría decirse, junto con Carlos de la Rica ${ }^{21}$, que su importancia fue vital como precursor del llamado 'realismo mágico' y como renovador de la poesía de posgue-

\footnotetext{
${ }^{16}$ Ángel Crespo, "La trayectoria literaria de Gabino-Alejandro Carriedo", El País (25-8-1985). Reproducido en Ángel Crespo, Las cenizas de la flor, Madrid (Júcar) 1987.

${ }^{17}$ Amador Palacios, Gabino-Alejandro Carriedo, su continente y su contenido, Palencia (Caja de Ahorros y Monte de Piedad de Palencia) 1984, pp.155-156.

${ }^{18}$ Antonio Martínez Sarrión, “Carriedo póstumo”, EL UROGALLO (diciembre 1988), pp.74-75.

${ }^{19}$ César Augusto Ayuso, "Gabino-Alejandro Carriedo en portugués. Un libro póstumo y definitivo”, Ínsula 510, año 1989, pp.9-10.

${ }^{20}$ Francisca Domingo Calle, "Introducción” a El libro de las premoniciones, Cuenca (E1 toro de barro) 1999, pp.7-15.

${ }^{21}$ Carlos de la Rica, "Un poeta de vanguardia exigente y total", Ya 9-9-1981.
} 
rra, tanto por su aportación creativa como por su apoyo incondicional a los nuevos poetas a través de El Pájaro de Paja o Poesía de España. Su conciencia social no hizo de él, sin embargo, un autor panfletario, sino que, más bien al contrario, lo mostró exigente y preocupado por la forma en sus composiciones en las que buscaba la diafanidad pretendiendo ante todo liberar al lenguaje poético de adornos innecesarios. Algún crítico como José Manuel Rozas ${ }^{22}$ considera que en el caso de Carriedo la conjunción de diferentes vertientes creativas no ha dado siempre los resultados que serían deseables, pues su sentido de lo lúdico se ha visto mitigado en exceso por la vertiente más experiencial y crítica del autor. Para Rozas el palentino habría alcanzado sus más altas cotas con dos libros significativos: Los animales vivos y Los lados del cubo.

Fanny Rubio ${ }^{23}$ ha señalado como algunas de las características más destacables de su vida y de su obra: su agudo sentido del humor, así como su labor de animador de empresas culturales y su desconfianza de la metafísica y de la retórica, pues llegaba a preguntarse si esta última no estaría en las antípodas de la poesía.

Junto a ellas, otras constantes que no se deben olvidar serían: el gusto por el lenguaje coloquial y agresivo, la originalidad en la elección de la materia poética, los juegos verbales, la ironía, el humor, el tremendismo, el cinismo, el distanciamiento, el sentimiento social y humano, la ternura o la orfebrería de la palabra. Su obra es, en buena medida, una crónica de la vida marcada por la presencia de la muerte, siendo ambas, en el fondo, dos caras de la misma medalla, el eterno vivir muriendo que tantas obras ha suscitado a lo largo de la historia de la literatura. Se ha señalado en más de una ocasión el carácter premonitorio de sus versos ${ }^{24}$ y Jaume Pont ${ }^{25}$ lo considera "uno de los líricos más innovadores y sugerentes" de la poesía española desde la posguerra.

Pese a la, en ocasiones, difícil catalogación de su obra bajo una única etiqueta, lo cual proporciona (frente a lo que pudiera pensarse) versatilidad a la misma, podríamos decir que con Gabino-Alejandro Carriedo estamos ante uno de esos extraños ejemplos de poeta atípico y desconocido para el lector común, en palabras de Ortega Aragón'26, cuya personalidad distinta se vislumbra en todas y cada una de sus composiciones. Se trata, pues, de un autor al que habría que reivindicar de cara a las nuevas generaciones, un 'poeta de culto', 'secreto', en palabras de Martínez Ruiz ${ }^{27}$ o de Antonio Martínez Sarrión en su prólogo a la antología ${ }^{28}$, de personalidad inclasificable, que supo estar por encima de las limitaciones de los movimientos en que militó, imprimiendo siempre a su obra su marcado sesgo personal. Carriedo se encuentra entre esos poetas que consiguieron, con su esfuerzo pausado e inquebrantable, horadar poco a poco el muro de oscurantismo avasallador de los años de posguerra.

\footnotetext{
${ }^{22}$ José Manuel Rozas, "Poesía de renovación y experimentación”, Literatura contemporánea en Castilla y León, Valladolid (Junta de Castilla y León) 1987, pp.129-133.

${ }^{23}$ Fanny Rubio, "El solitario", El País 10-9-1981.

${ }^{24}$ Victoriano Crémer, "Se nos ha muerto entre la sangre el poeta Gabino-Alejandro Carriedo", Sección 'Poesía y vida' en $L a$ hora leonesa 13-9-1981.

${ }^{25}$ Jaume Pont, "En la mort del poeta Gabino-Alejandro Carriedo", AVUI (1-10-1981), p.25.

${ }^{26}$ Gonzalo Ortega Aragón, "Sorprendente originalidad de Gabino-Alejandro Carriedo", Diario Palentino (24-11-1980), p.6.

${ }^{27}$ Florencio Martínez Ruiz, "Carriedo, la ironía como elemento crítico", $A B C$ (9-9-1981), p.30.

${ }^{28}$ Antonio Martínez Sarrión, "Prólogo" en Gabino-Alejandro Carriedo, Nuevo compuesto descompuesto viejo (Poesía 19481979), Madrid (Hiperión), pp.7-23.
} 